Bangladesh J. Bot. 49(2): 215-221, 2020 (June)

\title{
AMMI ANALYSIS OF GENOTYPE $\times$ ENVIRONMENT INTERACTION AND STABILITY OF SESAME GENOTYPES
}

\author{
Bhagwat Singh* and RaJani Bisen \\ Project Co-ordinating Unit (Sesame and Niger), JNKVV, Jabalpur (M.P.), India \\ Keywords: AMMI analysis, G × E interaction, IPCA, Stability
}

\begin{abstract}
The additive main effects and multiplicative interaction (AMMT) model for seed yield of 60 varieties of sesame per plant detected significant effects of the genotypes (17.87\% sum of squares (SS)), environments $(14.15 \%$ SS) and genotype $\times$ environment interaction $(67.99 \%$ SS). The model also extracted two significant interaction principal component analysis (IPCA) with a total of $79.9 \%$ SS and $67.8 \%$ corresponding degrees of freedom. Genotype TMV-7 (17.308 g/plant) followed by N-8 (13.994 g/plant) had the highest average yield which was much greater than the grand mean (10.976 g/plant) and declared as area specific adapted genotypes. Environments El, E2 and E4 were unfavorable while E3 is the most suitable as indicated by high mean value of IPCA 1 and low value of IPCA 2 .
\end{abstract}

\section{Introduction}

Sesame (Sesamum indicum L.) is one of the most ancient oilseed crops, commonly known as Til in India and used by human beings from ancient times. The genus Sesamum $(2 \mathrm{n}=26)$ is a member of Pedaliaceae which contains 16 genera and 36 species, most of which occur in Africa (Ashri 2007). Laurentin and Karlovsky (2006) studied 32 sesame accessions which were collected from five geographical regions representing the proposed diversity centers and found that there is very high genetic diversity among sesame collections from those regions. Kobayasi (1981) reported that about 36 species of sesame are said to exist and most of them are located in Africa, with a few in India. Bedigian et al. (2003) considered East Africa and India as early origins for sesame.

Chemical composition of seed shows that it contains $42-63 \%$ oil, $22-25 \%$ protein, $13.5 \%$ carbohydrate and 5\% ash (Tunde-Akintunde and Akintunde 2004 and Elleucha et al. 2007). The presence of sesamin and sesaminol lignans in its nonglycerol fraction contributed to oxidative stability and antioxidative activity of sesame oil (Wu 2007). Most abundant fatty acids present in sesame oil include: oleic acid (43\%), linoleic acid (35\%), palmitic acid (11\%) and stearic acid (7\%) contributing toward $96 \%$ of total fatty acids (Elleucha et al. 2007).

India holds a premier position in the global oilseed's scenario accounting for $29 \%$ of the total area and $26 \%$ of production. In India, sesame is cultivated in 17.138 lakh hectare with a production of 7.84 lakh tonnes and productivity of $457 \mathrm{~kg} / \mathrm{ha}$. Madhya Pradesh contributes 19.71 and $23.68 \%$ share of country's area (3.80 lakh ha) and production (1.94 lakh tonnes), respectively with productivity of $511 \mathrm{Kg} / \mathrm{ha}$ (DACNET, 2016-17) to improve the production and productivity of sesame in India evaluating different genotypes across different environments or the $\mathrm{G} \times \mathrm{E}$ interaction study might be important for supplying area specific or widely adapted improved seeds.

Genotype by environment interaction $(\mathrm{G} \times \mathrm{E}$ interaction) refers to the deviation in performance of any attributes of genotypes within the various growing environments across

*Author for correspondence: <bhagwat237@gmail.com>. 
locations and years. The presence of $\mathrm{G} \times \mathrm{E}$ interaction complicates the varietal selection process as it reduces the usefulness of genotypes by confounding their yield performance through minimizing the association between genotypic and phenotypic values (Farshadfar et al. 2012). However, it is possible to develop genotypes with low $\mathrm{G} \times \mathrm{E}$ interaction via sub-division of heterogeneous area into smaller-more homogeneous sub-regions and by selecting genotypes with a better stability across a wide range of environments (Farshadfar et al. 2011). So, G $\times \mathrm{E}$ interaction may be considered both as an opportunity and a challenge for breeders. AMMI is important to analyze multi-environment trials data and it interprets the effect of the genotype $(\mathrm{G})$ and Environments (E) as additive effects and the $\mathrm{G} \times \mathrm{E}$ as a multiplicative component (which are sources of variation) and submits it to principal component analysis. The AMMI procedure has been shown to increase estimation accuracy since it fits additive main effects for genotypes and environments by an ordinary ANOVA procedure and then applies PCA to the matrix of residuals of that remain after the fitting of main effects (Gauch 1988). In AMMI model the interaction $\left(\mathrm{GE}_{\mathrm{J}}\right)$ and the residual $(e, j)$ can be decomposed into several Interaction Principal Component Axes (IPCA) using PCA. The objective of this study was to determine the magnitude of GXE interaction and stability of sesame genotypes.

\section{Material and Methods}

The present investigation consisted of 60 genotypes (Table 1) collected from PC UNIT sesame and niger, JNKVV Jabalpur was carried out at Project Co-ordinating Unit (Sesame and Niger), JNKVV, Jabalpur (M.P.) during during Kharif 2016 (E1), summer, 2017 (E2), Kharif 2017 (E3) and summer, 2018 (E4). The experiment was laid out in RCBD with three replications and a total plot size of $12 \mathrm{~m}^{2}$.

Table 1. List of genotypes used in study.

\begin{tabular}{llllllll}
\hline S1. No. & Genotypes & Sl. No. & Genotypes & Sl. No. & Genotypes & S1. No. & Genotypes \\
\hline 1 & RT-127 & 16 & DS-5 & 31 & TMV-7 & 46 & KALIKA \\
2 & RT-346 & 17 & PT-1 & 32 & THILAK & 47 & KRISHNA \\
3 & RT-103 & 18 & N-32 & 33 & PKV-NT-11 & 48 & HIMA \\
4 & RT-54 & 19 & RAMA & 34 & YLM-17 & 49 & THILATHARA \\
5 & RT-46 & 20 & GT-4 & 35 & YLM-66 & 50 & N-8 \\
6 & GT-1 & 21 & T-4 & 36 & THILARANI & 51 & DS-1 \\
7 & GT-2 & 22 & AKT-101 & 37 & CO-1 & 52 & YLM-11 \\
8 & TKG-306 & 23 & NIRMALA & 38 & RT-125 & 53 & SEKHAR \\
9 & JTS-8 & 24 & USHA & 39 & RT-351 & 54 & JLT-7 \\
10 & TKG-55 & 25 & CHANDANA & 40 & GT-10 & 55 & PRACHI \\
11 & TKG-22 & 26 & SMARAK & 41 & BRIJESHWARI & 56 & TMV-4 \\
12 & JLT-408 & 27 & SAVITRI & 42 & RAJESHWARI & 57 & KANAK \\
13 & MT-75 & 28 & PKDS-8 & 43 & DSS-9 & 58 & SSD-5 \\
14 & VRI-1 & 29 & PKDS-11 & 44 & VINAYAK & 59 & JT-12(PKDS-12) \\
15 & VRI-2 & 30 & SWETHA TIL-1 & 45 & TARUN & 60 & TKG-21 \\
\hline
\end{tabular}

AMMI model analysis was carried out according to Gauch (1988) and AMMI's stability value (ASV) was calculated using the formula as suggested by Purchase (1997). 
Lewis' (1954) stability factor, Plaisted and Peterson's (1959) model, Wricke's (1962) Ecovalence method and Shukla's (1972) stability variance were also used for stability analysis.

\section{Results and Discussion}

The AMMI model for grain yield detected significant variation $(\mathrm{p}<0.001)$ for both the main and interaction effects indicating the existence of a wide range of variation between the genotypes, seasons and their interactions (Table 2). Genotypes had a lion share in grain yield variation and accounted about $17.87 \%$ of the total sum of squares indicating that the greatest source of variation for grain yield among the genotypes was mainly the inherent genetic component. Similar results were reported in sesame (Zenebe and Hussien 2009). Environments and interaction effects had 14.15 and $67.99 \%$ contribution for the total sum of squares, respectively. The AMMI model extracted two significant $(\mathrm{p}<0.001)$ IPCAs from the interaction component (Table 3). These two IPCAs accounted a total $79.9 \%$ of the interaction sum of squares with $67.8 \%$ corresponding degrees of freedom with a remaining considered as noise (Table 2). The extracted IPCAs are capable of providing information on the interaction effect although their degree decreases from the first to the last IPCAs. However, both the IPCAs could best explain the interaction sum of squares (Zobel et al . 1988). Accordingly, both IPCA's with a total of $67.99 \%$ sum of squares and $67.8 \%$ of corresponding degrees of freedom were used to explain the interaction effect.

Table 2. Combined AMMI analysis of variance for grain yield of sesame genotypes.

\begin{tabular}{llll}
\hline Source & \multicolumn{3}{l}{ Seed yield per plant } \\
\cline { 2 - 4 } & DF & MSS & $\%$ explained \\
\hline \multirow{2}{*}{ Trials } & 239 & 15.10 & - \\
Genotype & 59 & 10.93 & 17.87 \\
Environment & 3 & $170.25^{* * *}$ & 14.15 \\
G $\times$ E interaction & 177 & $13.86^{* * *}$ & 67.99 \\
PCA I & 61 & $18.01^{* * *}$ & 44.78 \\
PCA II & 59 & $14.59^{* * *}$ & 35.09 \\
Error & 480 & 1.09 & - \\
\hline
\end{tabular}

According to AMMI 1 biplot (Fig. 1), genotypes SWETHA TIL-1 (30), YLM-11 (52), TMV4 (56) and KANAK (57) were identified as stable. In AMMI 2 biplot (Fig. 2), the genotypes SAVITRI (27) were nearer to IPCA origin, hence these genotypes were stable over environments. Among the environments, environment III is most suitable as indicated by high mean value of IPCA 1 and low value of IPCA 2.

As depicted in Table 3 below the average grain yield of the tested sesame genotypes over the four environments was $10.976 \mathrm{~g} / \mathrm{plant}$. The TMV-7 (17.308 g/plant) had the highest average yield followed by N-8 (13.942 g/plant) and Vinayak (13.175 g/plant) while DSS-9 (7.492 g/plant) was the poorly yielding genotype). The magnitude (absolute value) of the IPCA scores of the genotypes is presented in Table 3. Genotypes with a greater IPCA score are the more responsive ones for the interaction effect and the more specifically adapted genotypes to a certain environment or location. In contrast to this, the genotypes with smaller IPCA scores were with lower interaction and are considered as widely adapted genotypes. Genotypes with greater 
magnitude of IPCA 1 such as Chandana (1.832), Usha (1.811) and Nirmala (1.713), were the more responsive and contributed largely to the interaction component and may be considered as a specifically adapted genotype. On the other hand, N-8 (-1.33) followed by MT-75 (-1.069) were the genotype with least contribution to the interaction component as they are with lower IPCA1 and mapped near to the bi-plot origin indicating their wider adaptability or stability (Table 3) which was also similar to other stability factor.

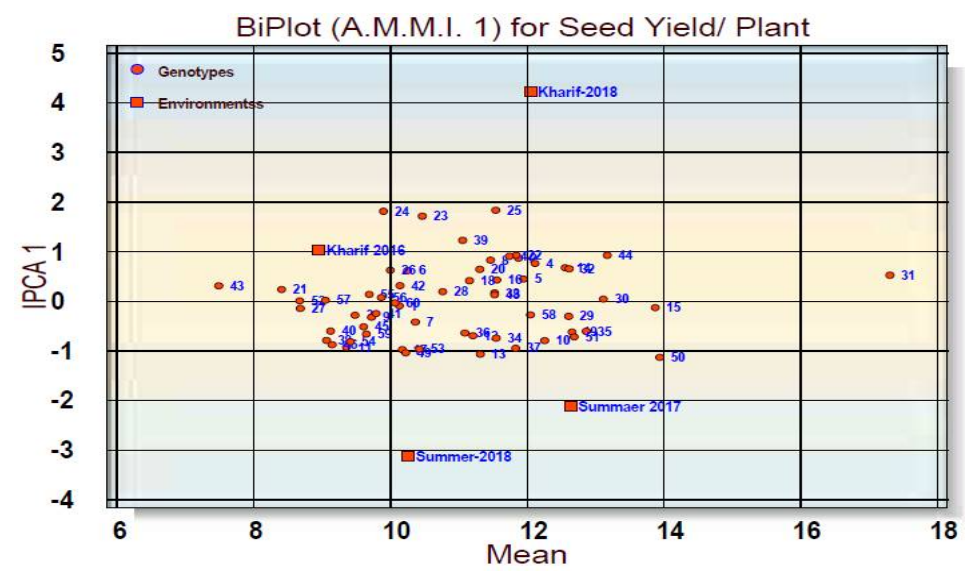

Fig. 1. Biplot (AMMI 1) for seed yield per plant in sesame.

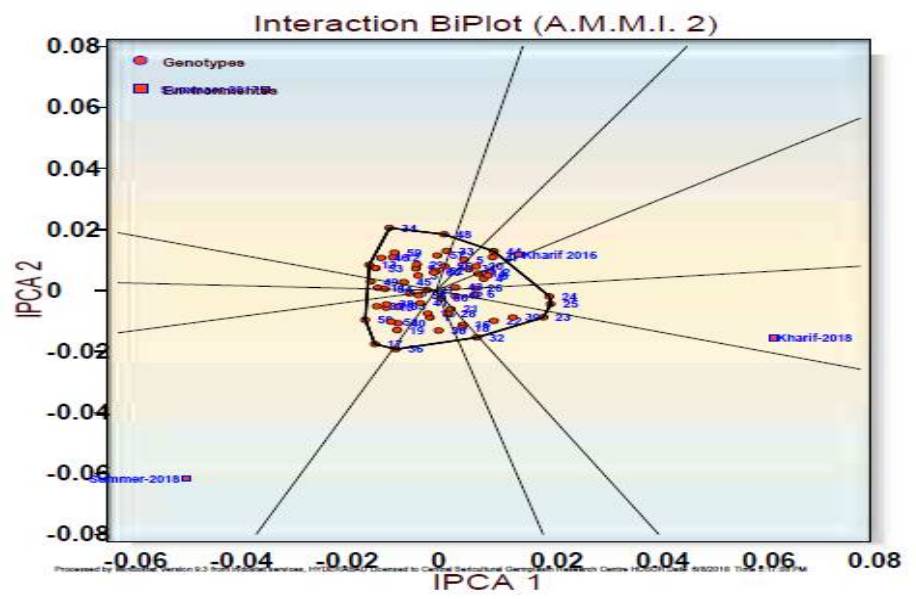

Fig. 2. Interaction biplot (AMMI 2) for seed yield per plant in sesame.

The ASV is the distance from the coordinate point to the origin in a two-dimensional scatter gram of IPCA 1 scores against IPCA 2 scores in the AMMI model (Purchase 1997). The genotypes with larger IPCA score, either negative or positive, are the more specifically adapted to certain environments and those with smaller IPCA scores indicate a more stable genotype across environments. Accordingly, Savitri with lowest ASV (0.186) followed by TMV-4 (0.218) and SSD-5 (0.376) were the most stable genotypes, whereas, Chandana (2.363) followed by Usha (2.316) (Table 3) ranked as less stable and more sensitive genotypes to environmental change. 
The genotypes, TMV-4 (1.089) and SSD-5 (1.234) showed stable performance as indicated by low stability factor values when compared with other genotypes (Table 3).

Plaisted and Peterson (1959) described a procedure to characterize the stability of the performance of several varieties. A combined analysis of variance at all locations was computed for each pair of varieties, $\mathrm{g}(\mathrm{g}-\mathrm{l}) / 2$ pairs for $\mathrm{g}$ varieties and an estimate of genetic variance was obtained for each pair and for each genotype. The genotype with the smallest mean value was considered to be the most stable. The genotypes, Savitri (7.15) and DSS-9 (7.548) manifested desirable performance as evidenced from very low variance due to genotype - environment interaction (Table 3).

The lower the ecovalence of a genotype, the smaller its fluctuations from the experimental mean under different environments and thus a smaller share in the interaction sum of squares. Accordingly, the genotype with the least ecovalence can be considered as more stable and the genotypes with a high ecovalence have a poor stability. Savitri (1.310) and DSS-9 (3.634) showed desirable performance with less contribution to genotype environment interaction as evidenced from low ecovalence values (Table 3).

It is a measure of unbiased partitioning of the total variation due to genotype $\times$ environment interaction into components assignable to individual cultivars. It indicated that the cultivars with significant mean squares were suggested to be unstable i.e., non-significance showed stability. The genotype, Savitri (0.213) and DSS-9 (1.014) showed consistent performance as evidenced by lower $\mathrm{S}^{2}$ values (Table 3).

Table 3. IPCA score and stability parameter from AMMI model.

\begin{tabular}{|c|c|c|c|c|c|c|c|c|}
\hline Genotype & PCA I & PCA II & ASV & $\begin{array}{l}\text { Rank } \\
\text { (ASV) }\end{array}$ & $\begin{array}{l}\text { Trait } \\
\text { mean }\end{array}$ & $\begin{array}{l}\text { Rank } \\
\text { (trait) }\end{array}$ & $\begin{array}{l}\text { Ecovalence } \\
\text { wricke }\end{array}$ & $\begin{array}{l}\text { Plaisted \& } \\
\text { Peterson }\end{array}$ \\
\hline RT-127 & -0.10 & -0.68 & 0.69 & 17.00 & 10.13 & 21.00 & 14.18 & 9.34 \\
\hline RT-346 & 0.87 & 0.45 & 1.19 & 38.00 & 11.87 & 45.00 & 30.71 & 12.14 \\
\hline RT-103 & -0.28 & 0.37 & 0.52 & 9.00 & 9.48 & 11.00 & 7.80 & 8.25 \\
\hline RT-54 & 0.76 & 0.29 & 1.01 & 27.00 & 12.12 & 48.00 & 32.93 & 12.51 \\
\hline RT-46 & 0.45 & 0.77 & 0.96 & 24.00 & 11.95 & 46.00 & 34.65 & 12.81 \\
\hline GT-1 & 0.62 & -0.11 & 0.79 & 19.00 & 10.25 & 25.00 & 15.67 & 9.59 \\
\hline GT-2 & -0.42 & -0.07 & 0.54 & 10.00 & 10.37 & 26.00 & 6.75 & 8.08 \\
\hline TKG-306 & 0.83 & 0.38 & 1.12 & 35.00 & 11.47 & 36.00 & 37.68 & 13.32 \\
\hline JTS-8 & -0.32 & 0.55 & 0.69 & 15.00 & 9.72 & 15.00 & 16.37 & 9.71 \\
\hline TKG-55 & -0.80 & -0.44 & 1.10 & 34.00 & 12.26 & 49.00 & 44.54 & 14.48 \\
\hline TKG-22 & -0.93 & 0.07 & 1.19 & 37.00 & 9.36 & 9.00 & 28.90 & 11.83 \\
\hline JLT-408 & -0.70 & 0.83 & 1.22 & 40.00 & 11.21 & 33.00 & 38.19 & 13.41 \\
\hline MT-75 & -1.07 & 0.64 & 1.51 & 51.00 & 11.32 & 35.00 & 54.99 & 16.25 \\
\hline VRI-1 & 0.68 & 0.42 & 0.96 & 25.00 & 12.56 & 50.00 & 20.51 & 10.41 \\
\hline VRI-2 & -0.13 & -0.58 & 0.61 & 12.00 & 13.87 & 58.00 & 25.06 & 11.18 \\
\hline DS-5 & 0.43 & -0.87 & 1.03 & 30.00 & 11.56 & 41.00 & 29.72 & 11.97 \\
\hline PT-1 & -0.98 & -1.35 & 1.84 & 56.00 & 10.17 & 23.00 & 85.56 & 21.43 \\
\hline $\mathrm{N}-32$ & 0.41 & -0.94 & 1.08 & 33.00 & 11.16 & 32.00 & 34.52 & 12.78 \\
\hline RAMA & -0.62 & -1.00 & 1.28 & 43.00 & 12.66 & 53.00 & 45.66 & 14.67 \\
\hline GT-4 & 0.64 & 0.61 & 1.02 & 29.00 & 11.31 & 34.00 & 36.99 & 13.20 \\
\hline $\mathrm{T}-4$ & 0.23 & -0.47 & 0.56 & 11.00 & 8.41 & 2.00 & 8.45 & 8.36 \\
\hline AKT-101 & 0.93 & -0.77 & 1.41 & 47.00 & 11.84 & 44.00 & 64.33 & 17.84 \\
\hline Nirmala & 1.71 & -0.68 & 2.29 & 58.00 & 10.47 & 28.00 & 115.59 & 26.52 \\
\hline
\end{tabular}


Table contd.

\begin{tabular}{|c|c|c|c|c|c|c|c|c|}
\hline Genotype & PCA I & PCA II & ASV & $\begin{array}{l}\text { Rank } \\
\text { (ASV) }\end{array}$ & $\begin{array}{l}\text { Trait } \\
\text { mean }\end{array}$ & $\begin{array}{l}\text { Rank } \\
\text { (trait) }\end{array}$ & $\begin{array}{l}\text { Ecovalence } \\
\text { wricke }\end{array}$ & $\begin{array}{l}\text { Plaisted \& } \\
\text { Peterson }\end{array}$ \\
\hline Usha & 1.81 & -0.15 & 2.32 & 59.00 & 9.90 & 18.00 & 113.61 & 26.19 \\
\hline Chandana & 1.83 & -0.34 & 2.36 & 60.00 & 11.54 & 39.00 & 141.96 & 30.99 \\
\hline Smark & 0.62 & 0.05 & 0.80 & 20.00 & 10.00 & 19.00 & 22.77 & 10.79 \\
\hline Savitri & -0.15 & 0.01 & 0.19 & 1.00 & 8.68 & 4.00 & 1.31 & 7.15 \\
\hline PKDS-8 & 0.19 & -0.59 & 0.64 & 14.00 & 10.77 & 29.00 & 64.35 & 17.84 \\
\hline PKDS-11 & -0.30 & 0.65 & 0.76 & 18.00 & 12.61 & 51.00 & 15.92 & 9.63 \\
\hline Swetha Till-1 & 0.04 & -1.01 & 1.01 & 26.00 & 13.12 & 56.00 & 41.13 & 13.90 \\
\hline TMV-7 & 0.52 & 0.53 & 0.85 & 21.00 & 17.31 & 60.00 & 17.90 & 9.97 \\
\hline THILAK & 0.65 & -1.18 & 1.45 & 50.00 & 12.62 & 52.00 & 70.13 & 18.82 \\
\hline PKV-NT-11 & 0.17 & 0.99 & 1.02 & 28.00 & 11.52 & 37.00 & 41.16 & 13.91 \\
\hline YLM-17 & -0.74 & 1.57 & 1.84 & 57.00 & 11.55 & 40.00 & 97.60 & 23.48 \\
\hline YLM-66 & -0.61 & -0.42 & 0.88 & 23.00 & 12.87 & 55.00 & 23.25 & 10.87 \\
\hline Thilarani & -0.64 & -1.48 & 1.69 & 54.00 & 11.09 & 31.00 & 78.97 & 20.32 \\
\hline $\mathrm{CO}-1$ & -0.95 & -0.40 & 1.27 & 41.00 & 11.83 & 43.00 & 34.57 & 12.79 \\
\hline RT-125 & -0.79 & -0.35 & 1.07 & 32.00 & 9.07 & 6.00 & 28.31 & 11.73 \\
\hline RT-351 & 1.23 & -0.68 & 1.71 & 55.00 & 11.06 & 30.00 & 75.26 & 19.69 \\
\hline GT-10 & -0.60 & -0.83 & 1.13 & 36.00 & 9.12 & 7.00 & 34.91 & 12.85 \\
\hline Brijeshwari & -0.25 & -0.32 & 0.45 & 6.00 & 9.79 & 16.00 & 17.38 & 9.88 \\
\hline Rajeshwari & 0.31 & -0.14 & 0.42 & 5.00 & 10.14 & 22.00 & 3.92 & 7.60 \\
\hline DSS-9 & 0.31 & 0.07 & 0.40 & 4.00 & 7.49 & 1.00 & 3.63 & 7.55 \\
\hline Vinayak & 0.92 & 0.99 & 1.54 & 52.00 & 13.18 & 57.00 & 175.42 & 36.66 \\
\hline Tarun & -0.52 & 0.21 & 0.69 & 16.00 & 9.61 & 12.00 & 17.65 & 9.92 \\
\hline Kalika & -0.88 & 0.82 & 1.39 & 46.00 & 9.15 & 8.00 & 46.23 & 14.77 \\
\hline Krishna & 0.90 & 0.84 & 1.42 & 49.00 & 11.74 & 42.00 & 67.27 & 18.33 \\
\hline Hima & 0.13 & 1.41 & 1.42 & 48.00 & 11.53 & 38.00 & 66.29 & 18.17 \\
\hline N-32 & -1.04 & 0.22 & 1.35 & 44.00 & 10.22 & 24.00 & 38.82 & 13.51 \\
\hline $\mathrm{N}-8$ & -1.13 & -0.74 & 1.62 & 53.00 & 13.94 & 59.00 & 75.90 & 19.80 \\
\hline DS-1 & -0.72 & -0.79 & 1.21 & 39.00 & 12.69 & 54.00 & 38.67 & 13.49 \\
\hline YLM-11 & 0.01 & 0.48 & 0.48 & 8.00 & 8.68 & 3.00 & 7.56 & 8.21 \\
\hline Sekhar & -0.96 & 0.56 & 1.35 & 45.00 & 10.42 & 27.00 & 42.41 & 14.12 \\
\hline JLT-7 & -0.82 & 0.04 & 1.05 & 31.00 & 9.42 & 10.00 & 23.64 & 10.94 \\
\hline PRACHI & 0.14 & 0.61 & 0.63 & 13.00 & 9.69 & 14.00 & 12.40 & 9.03 \\
\hline TMV-4 & 0.07 & -0.20 & 0.22 & 2.00 & 9.87 & 17.00 & 9.14 & 8.48 \\
\hline Kanak & 0.02 & 0.88 & 0.88 & 22.00 & 9.05 & 5.00 & 22.61 & 10.77 \\
\hline SSD-5 & -0.28 & -0.12 & 0.37 & 3.00 & 12.05 & 47.00 & 4.94 & 7.77 \\
\hline JT-12 & -0.66 & 0.95 & 1.27 & 42.00 & 9.65 & 13.00 & 41.22 & 13.92 \\
\hline TKG-21 & -0.03 & 0.45 & 0.45 & 7.00 & 10.07 & 20.00 & 6.12 & 7.97 \\
\hline
\end{tabular}

Table 4. IPCA score and environmental index.

\begin{tabular}{ccccc}
\hline Code & Env. mean & Env. index & PCA I & PCA II \\
\hline E1 & 8.954 & -2.022 & 1.030 & 0.680 \\
E2 & 12.638 & 1.663 & -2.130 & 3.859 \\
E3 & 12.049 & 1.073 & 4.221 & -0.911 \\
E4 & 10.262 & -0.714 & -3.121 & -3.628 \\
\hline
\end{tabular}

The environments had different mean grain yields (Table 4) and this indicates that the different environments were not equally favorable or unfavorable for the genotypes grown under them. Environments are often classified as favorable and unfavorable ones based on the environmental index (EI) where environments with a negative index considered as unfavorable 
and those with positive regarded as favorable (Farshadfar 2008). Accordingly, El had a negative environmental index $(-2.022)$ and was classified as the least favorable environment while E2 had the highest positive environmental index (1.663) and considered as the most favorable environment (Table 4). In general El and E4 both with negative environmental index had below average mean yield and considered as unfavorable environments. Whereas, E2 and E3 with positive and significant environmental index had above average mean yield performance and classified as favorable environments.

\section{References}

Plaisted RL and Peterson LC 1959. A technique for evaluating the ability of selection to yield consistently in different seasons or locations. American Potato Journal 36: 381-385.

Ashri A 2007. Genetic resources, chromosome engineering and crop improvement in sesame (Sesamum indicum L.). Oilseed crops. CRC press, Boca Raton 4: 231-289

Bedigian D 2003. Evolution of sesame revisited: Domestication, diversity and prospects. Genetics Resources and Crop Evolution 50: 779-787.

DACNET 2016-17. 4th Advanced Estimation. GOI.

Elleucha M, Besbesa S, Roiseuxb O, Bleckerb C and Attiaa H 2007. Quality characteristics of sesame seeds and by-products. Food Chemistry 103(2): 255-688

Farshadfar E 2008. Incorporation of AMMI stability value and grain yield in a single non-parametric index (GSI) in bread wheat. Pak. J. Biol. Sci. 11: 1791-1796.

Farshadfar E, Geravandi and Z. Vaisi 2012. Chromosomal localization of QTLs controlling genotypey $\times$ environment interactions in barley. Int. J. Agric. Crop Sci. 4: 317-324.

Farshadfar E, Z Vaisi and A Yaghotipoor 2011. Non-parametric estimation of phenotypic stability in wheatbarley disomic addition lines. Ann. Biol. Res. 2: 586-598.

Gauch HG 1988. Model selection and validation for yield liiuls with inleiaction. Biomeliics 44: 705-715.

Kobayashi T 1981. The wild and cultivated species in the genus Sesamum. In: Sesame : status and improvement, Proceed. Expert Consultation Rome, Italy, 8-12 December, 1980. FAO, Rome, Italy 157162.

Laurentin HE, Karlovsky P 2006. Genetic relationship and diversity in a sesame (Sesamum indicum L.) germplasm collection using amplified fragment length polymorphism (AFLP). BMC Genetics 7: 10.

Lewis D 1954. Genotype - environment interaction. A relationship between dominance, heterosis, phenotypic stability and variability. Heredity 8: 333- 356 .

Purchase JL 1997. Parametric analysis to describe G x E interaction and yield stability in winter wheat. Ph.D Dissertation. Department of Agronomy, Faculty of Agriculture, University of the Free state, Bloemfontein, South Africa. pp. 148.

Shukla GK 1972. Some statistical aspects of partitioning genotype-environment components of variability. Heredity 29: 237-245.

Tunde-Akintunde TY and Akintunde BO 2004. Some physical properties of sesame seed. Biosystems Engineering 88: 127-129.

Wricke O 1962. Uber eine Methode zur Erfassung derkologischen strenb reite in Feldversuchen. Z Pflanzenxaxht 47: 92-96.

Wu W H 2007. The contents of lignans in commercial sesame oils of Taiwan and their changes during heating. Food Chemistry 104(1): 341.

Zenebe $\mathrm{M}$ and Hussien 2009. Study on genotype $\times$ environment interaction of yield in sesame (Sesamum indicum L.). J. Phytol, 1: 199-205.

Zobel RW, Wright MJ and Gauch HG 1988. Statistical analysis of a yield trial. Agron. J. 80: 388-393. 